Vol. 2, n. 3 - Edição Especial: Ciclos Formativos em Ensino de Ciências.

\title{
Estratégias de leitura de Textos de Divulgação Científica e a constituição docente de uma Professora de Química
}

\section{Strategies for Reading Scientific Dissemination Texts and the Teaching Constitution of a Chemistry Teacher}

\author{
Camila Carolina Colpo (camilacolpo@hotmail.com) \\ Universidade Federal da Fronteira Sul. \\ Programa de Pós Graduação em Ensino de Ciências- PPGEC/ UFFS. \\ Bolsista CAPES/DS
}

\begin{abstract}
Resumo: O presente relato contempla uma narrativa de uma professora de Química que fez uso de estratégias de leitura de Textos de Divulgação Científica (TDC) durante a formação inicial e, atualmente no Mestrado Acadêmico. A narrativa descreve o uso dos TDCs em diversos espaços de formação, que contemplam desde um Grupo de Estudos que realiza leitura interativa de TDCs, como os estágios de docência, o Trabalho de Conclusão de Curso, e, atualmente uma pesquisa a nível de mestrado com a Temática. $\mathrm{O}$ foco principal desses relatos de minha vivência formativa é a minha formação como professora capaz de mediar a leitura em espaços de ensino e, as potencialidades dos TDCs como ferramenta didática em sala de aula, com foco na significação conceitual em Química e a importância do TDC na formação inicial de professores.
\end{abstract}

Palavras-chave: Grupo de Estudos; Formação de professores; Leitura.

Abstract: This report contemplates the narrative of a chemistry teacher who made use of reading strategies as stalk-to-talk of Scientific Dissemination Texts (SDT) during her initial formation as a teacher and, still use the same technic during the Post Graduated Program. The narrative describes the use of SDTs in different spaces and occasions, which include Study Groups that leads to an interactive/participative moment reading of SDTs, such as the teaching practice, Coursework, and current research at the master level with the same SDTs approach theme. The main focus of these accounts of my formative experience is my education as a teacher who can mediate reading in teaching spaces and the potentialities of SDTs as a didactic tool in the classroom, focusing on the conceptual significance in Chemistry and the importance of SDT in initial teacher education.

Keywords: Study Group; Teacher training; Reading.

\section{CONTEXTUALIZAÇÃo}

O presente relato contempla um diálogo a cerca da minha trajetória acadêmica, a partir da participação em um Grupo de Estudos que realiza práticas de leitura interativa de Textos de Divulgação Científica (TDC) no âmbito do curso de Química Licenciatura 


\section{Vol. 2, n. 3 - Edição Especial: Ciclos Formativos em Ensino de Ciências.}

da Universidade Federal da Fronteira Sul (UFFS), campus Cerro Largo/RS. Tal Grupo de Estudos desenvolve suas atividades desde setembro de 2016 e é composto por licenciandos, egressos e professoras formadoras do curso de Química Licenciatura, alunos do Ensino Médio (bolsista PIBIC-EM) e professor da rede básica de ensino, supervisor do PIBID Química. São realizados encontros mensais, nos quais são desenvolvidos diálogos referentes aos TDCs previamente lidos pelos participantes. Os diálogos são realizados a partir de diferentes estratégias de leitura elaboradas e conduzidas pelos integrantes do grupo, a fim de contribuir para a utilização dos TDCs em futuros/atuais espaços de atuação dos professores.

A minha participação no Grupo de Estudos se deu desde a sua criação, perpassando a formação inicial, durante o curso de Química Licenciatura, e atualmente durante o programa de mestrado acadêmico em Ensino de Ciências- PPGEC/ UFFS. O interesse pelos TDCs surgiu anteriormente à criação do grupo, por curiosidade em conhecer um pouco mais destes textos, que para mim tinham uma linguagem acessível, contemplavam aspectos da evolução da Ciência e traziam aspectos da construção do conhecimento científico que os textos que eu estava acostumada a ler (livro didático), não traziam. Para tanto, vi nestes textos, antes mesmo de revisar o que a literatura dizia sobre a temática, uma potencialidade didática muito grande, pois me vi como estudante, e vislumbrei que eu teria conhecido um pouco mais sobre Ciência se tivesse um TDC para me auxiliar. No contexto em que eu estava inserida, que era um curso de licenciatura, frente a propor uma estratégia didática, vi no TDC um grande potencial como ferramenta de mediação entre professor em formação e aluno.

Os TDCs, segundo Fatareli et al. (2015, p. 11) "apresentam linguagem simples e não trazem muitos termos técnico científicos, sendo repleto de procedimentos explicativos, os quais facilitam a compreensão do leitor frente aos aspectos mais específicos". Cabe destaque também que, "embora não tenham sido produzidos com fins didáticos, há nesses textos um endereçamento bastante evidente para professores e alunos, especialmente pela forma como as temáticas científicas são tratadas" (FERREIRA e QUEIROZ, 2015, p. 132). E, foi esta forma como o TDC apresenta as temáticas científicas que me aproximaram dele. Portanto, a partir dessas especificidades de sua 


\section{Vol. 2, n. 3 - Edição Especial: Ciclos Formativos em Ensino de Ciências.}

linguagem e posteriormente da participação no Grupo de Estudos e em pesquisas voltadas à leitura interativa de TDCs que pude ampliar a minha visão em relação aos textos, às práticas de leitura que o contemplam e as possibilidades deste na minha formação como uma professora capaz de mediar a leitura de um TDC em sala de aula.

A importância da formação de um professor leitor está em possibilitar que os professores possam ampliar o seu olhar para além da leitura enquanto ferramenta de ensino e busca de informações em um texto (FLÔR,2015, p. 45), e, ao considerar a prática da leitura como sendo um processo de interação entre o leitor e o texto, onde ler é se posicionar frente à ele (SOLÉ, 1998, p. 22), o professor leitor se torna um mediador de leitura em sala de aula.

No âmbito do Grupo de Estudo são realizadas atividades que buscam a formação de um professor leitor crítico e ativo, capaz de fomentar, em sala de aula, estratégias de leitura que motivem os estudantes a se posicionar frente a um texto, atribuindo significado à ele. Portanto, neste relato, trago vivências a partir da participação no Grupo e a implicações destas na minha formação.

\section{COMPREENSÕES E DISCUSSÕES}

Neste espaço, apresento um diálogo acerca de algumas as estratégias de leitura de TDC que fiz uso e das implicações destas para a minha formação. De início, fui atraída pelos TDCs pela sua linguagem e, em seguida, pelas possibilidades da sua utilização em sala de aula. A primeira atividade usando TDC desenvolvida por mim foi durante o Componente Curricular (CCR) de Iniciação à prática de Pesquisa, CCR obrigatório do curso de Química Licenciatura, que tem por objetivo a elaboração de um projeto de pesquisa à ser desenvolvido em um estágio em espaços não-formais de ensino.

Durante tal CCR tive a oportunidade de revisar o que a literatura trazia sobre o uso do TDC e da prática de leitura em sala de aula e elaborar a minha primeira estratégia de leitura de TDC. Posteriormente, durante o CCR de estágio não formal, tal estratégia de leitura de TDC foi desenvolvida e mediada por mim e meu grupo de estágio. A atividade consistiu em oficinas de leitura em grupo de um TDC com os alunos, que 


\section{Vol. 2, n. 3 - Edição Especial: Ciclos Formativos em Ensino de Ciências.}

culminaram na aplicação de um jogo didático no final. A opção por oficinas de leitura de TDCs esteve condicionada ao nosso interesse pela linguagem desses textos, que segundo, Ferreira e Queiroz (2012) apresentam três características principais, a saber, a didaticidade, a laicidade e a cientificidade. Segundo as autoras

os traços de cientificidade são aqueles típicos do discurso científico. [...]. Os traços de laicidade compreendem elementos inerentes ao discurso cotidiano, os quais compreendem as várias formas de contextualização. Os traços de didaticidade são próprios do discurso didático, os quais incluem procedimentos como explicações, recapitulações, orientações metodológicas. (FERREIRA; QUEIROZ, 2012, p. 23)

A meu ver, a estratégia de leitura proposta e mediada por uma professora em formação, possibilitou aos estudantes envolvidos na atividade um olhar diferenciado para os conceitos que seriam estudados e, me possibilitou uma primeira experiência com uso do TDC em sala de aula, onde eu fui capaz de identificar a importância da mediação da leitura de TDCs e do planejamento do professor ao fazer uso de tal estratégia em contexto escolar.

Posteriormente, houve a criação do Grupo de Estudos no curso de Química Licenciatura, do qual fui bolsista voluntária ${ }^{1}$ durante o primeiro ano e sou colaboradora ${ }^{2}$ do projeto de pesquisa que culminou na criação do Grupo. O Grupo de Estudos está ativo desde a sua criação, a saber setembro de 2016 e realiza encontros mensais para análise e discussão de TDCs.

Ao iniciarmos a pesquisa, o maior desafio foi nos ambientarmos com a temática e para tanto realizamos alguns trabalhos de revisão, a fim de aproximar o referencial das atividades desenvolvidas. A revisão na literatura apontou para as especificidades da linguagem do discurso de divulgação científica, contemplado nos TDCs, a importância de espaços de leitura em sala de aula, e principalmente a mediação do professor (WENZEL et al, 2018).

Já no âmbito do Grupo de Estudos realizamos um levantamento entre os participantes, a fim de traçar um perfil dos leitores as principais motivações para realizar

\footnotetext{
${ }^{1}$ Edital 315/UFFS/2016

${ }^{2}$ Chamada Universal MCTI/CNPq No 1/2016
} 


\section{Vol. 2, n. 3 - Edição Especial: Ciclos Formativos em Ensino de Ciências.}

as leituras. O perfil indiciou que a maioria dos participantes não conheciam os TDCs ou tiveram acesso a eles apenas na Graduação e que, em âmbito escolar realizavam em sua maioria, leituras literárias, porém se mostraram motivados com a oportunidade de conhecer os TDCs realizar a leitura de tais textos no âmbito do Grupo de Estudos (COLPO; MARTINS; WENZEL, 2017).

Durante os encontros do Grupo de Estudos, que são mensais, foram dialogados até então (agosto de 2019) alguns livros de Divulgação Científica, a saber: Tio Tungstênio: memórias de uma infância química de autoria de Oliver Sacks, Barbies, Bambolês e Bolas de Bilhar, de autoria de Joe Schwarcz e, O que Einstein disse ao seu cozinheiro, volume 1, de autoria de Robert Wolke, A Invenção do Ar e O Mapa Fantasma, de autoria de Steven Johnson., De que são feitas as coisas, de autoria de Mark Miodownik e $O$ polegar do violinista, de autoria de Sam Kean. E a lista não vai parar por aí. Para tanto, são realizadas diversas estratégias de leitura, que possibilitam as discussões sobre as temáticas abordadas no TDC.

Em Tio Tungstênio, utilizamos a elaboração de perguntas como estratégia de leitura. Tais perguntas foram elaboradas pelos participantes e trazidas para discussão durante os encontros. Elas foram posteriormente analisadas e indiciaram tanto um posicionamento maior dos participantes do Grupo de Estudos frente ao texto, quanto a validade da estratégia de formular perguntas sobre um texto para a qualificação do processo de leitura (WENZEL; MARTINS; COLPO, 2018).

Em Barbies, Bambolês e Bolas de Bilhar ${ }^{3}$ utilizamos estratégias de leitura variadas para a discussão dos capítulos, sendo as principais o uso de imagens, desenhos, formulações de perguntas e análise de rótulos. Aqui, cabe destaque para uma das estratégias de leitura utilizadas, que foi o uso de imagens para socialização dos subcapítulos do primeiro capítulo do livro em questão. Tal estratégia se mostrou válida, pois indiciou que a escolha das imagens para representar um subcapítulo caracteriza uma interação com o texto, o que culmina em uma apropriação da linguagem científica. (COLPO, WENZEL, 2018). Também, para o livro O que Einstein disse ao seu cozinheiro,

\footnotetext{
${ }^{3}$ As estratégias de leitura utilizadas foram relatadas em um trabalho submetido e aceito pela revista Ciência em Tela, em maio de 2019.
} 


\section{Vol. 2, n. 3 - Edição Especial: Ciclos Formativos em Ensino de Ciências.}

Volume 1, a estratégia de leitura adotada para a socialização do livro foi similar à anterior, com divisão por capítulos e discussão durante os encontros.

Para os livros A Invenção do Ar, O Mapa Fantasma, De que são feitas as coisas e, $O$ Polegar do Violinista a estratégia de leitura adotada consistiu no Mapeamento dos livros. O Mapeamento é uma estratégia de análise de TDCs, proposta por Ferreira e Queiroz (2011) que considera seu conteúdo e sua forma, destacando os conteúdos contemplados de maneira geral (conteúdos da Química, Fronteiras e Temas Transversais), de maneira específica (Temática, contexto e características da abordagem científica) e, a forma do texto (estrutura, linguagem e recursos visuais). O mapeamento está muito presente no Grupo de Estudos e continuará sendo desenvolvido com outros livros.

O meu Trabalho de Conclusão de Curso ${ }^{4}$ (TCC), foi fruto da análise da estratégia de leitura utilizada no capítulo 3 do livro Barbies, Bambolês e Bolas de Bilhar, intitulado Crimes Químicos que consistiu na proposição de perguntas sobre o capítulo e a partir da análise das respostas à perguntas indiciar a interação do leitor com o texto e a sua motivação para a leitura. (WENZEL, COLPO, 2019)

Culminando também da participação no Grupo de Estudos, destaco uma prática de leitura desenvolvida durante o CCR de Estágio curricular Supervisionado IV: Química para o Ensino Médio, no qual desenvolvi uma aula com leitura de TDC sobre a temática radioatividade, onde a leitura fundamentou a elaboração de seminários sobre a temática pelos alunos e contribuiu no sentido de inicia-los nessa linguagem, que utiliza termos muito específicos da Ciência. A atividade foi válida no sentido de aproximar os termos específicos da linguagem química ao cotidiano dos estudantes, com destaque para a mediação da atividade de leitura pela professora leitora em formação (WENZEL; COLPO, 2018).

A partir das estratégias de leitura apresentadas, afirmo as potencialidades do uso do TDC na formação do leitor, como estratégia didática visando a significação conceitual em Química e também, a importância do TDC na formação inicial e continuada de

\footnotetext{
${ }^{4}$ Interações discursivas nas leituras de textos de divulgação científica possibilitadas por uma estratégia de leitura (Disponível em: http://rd.uffs.edu.br/handle/prefix/1862).
} 


\section{Vol. 2, n. 3 - Edição Especial: Ciclos Formativos em Ensino de Ciências.}

professores, a fim de que o professor aprenda o que é um TDC e as especificidades de sua linguagem para poder mediar estratégias de leitura a partir dele em sala de aula.

\section{CONSIDERAÇÕES}

Durante a minha formação inicial, o uso do TDC esteve muito presente. Como já descrito, além da participação no Grupo de Estudos, que foi o que motivou os estudos e a aproximação com a temática, fiz uso do TDC em práticas de Ensino dos CCRs do Curso de Química Licenciatura, como também em estágios de docência.

Agora, durante a Pós Graduação o desafio também é fazer uso de TDCs para além do Grupo de Estudos, como mediadora de estratégias de leitura de TDCs na formação inicial de professores de Química, visando a significação conceitual de conceitos científicos, o mapeamento de TDCs, e a disseminação do seu uso. Acredito que com a pesquisa do mestrado sobre a temática, será possível compreender melhor tanto o papel do TDC na formação inicial de professores, quanto as suas potencialidades como facilitador da significação da linguagem científica.

Ainda participo ativamente do Grupo de estudos e viso continuar ampliando os diálogos sobre o uso de TDCs, divulgando os resultados das atividades desenvolvidas no grupo, bem como ampliando as discussões pertinentes ao uso de TDCs na formação inicial de professores e a relatando as possibilidades do uso de estratégias de leitura de TDCs em sala de aula.

\section{REFERÊNCIAS}

COLPO, C. C.; MARTINS, J. L. de C.; WENZEL, J. S.; As leituras realizadas pelos estudantes de um curso de licenciatura em química: suas motivações e o perfil de leitor. In: E-book do $37^{\circ}$ Encontro de Debates sobre o Ensino de Química : EDEQ - 37 anos: rodas de formação de professores na Educação Química, 09 e 10 de novembro de 2017 [recurso eletrônico] /Aline Machado Dorneles, Edi Morales Pinheiro Junior e Maria do Carmo Galiazzi (organizadores). - Rio Grande : Ed. da Furg, 2018. p. 


\section{Vol. 2, n. 3 - Edição Especial: Ciclos Formativos em Ensino de Ciências.}

COLPO, C. C.; WENZEL, J.S.; O uso de imagens na prática de leitura interativa de Textos de Divulgação Científica. Anais do $38^{\circ}$ EDEQ - Encontro de Debates sobre o Ensino de Química. Canoas- RS, 2018

FATARELI, E. F., MASSI,L., FERREIRA, L. N. A., QUEIROZ, S. L. Mapeamento de Textos de Divulgação Científica para Planejamento de Debates no Ensino de Química. Química Nova na Escola. Vol. 37, N 1, p. 11-18, FEVEREIRO 2015

FERREIRA, L.N.A.; QUEIROZ, S.L. Artigos da revista Ciência Hoje como recurso didático no ensino de química. Química Nova, v. 34, n. 2, p. 354-360, 2011

FERREIRA, L. N. A.; QUEIROZ, S. L. Características discursivas de artigos de divulgação científica relacionados à química. Revista Electrónica de Enseñanza de las Ciencias. Vol. 11, $\mathrm{N}^{\mathrm{o}}$ 1, p. 21-42, 2012

FERREIRA, L. N. A., QUEIROZ, S. L. Utilização de Textos de Divulgação Científica em salas de aula de Química. In: CUNHA, M. B., GIORDAN, M. (Orgs). Divulgação Científica na sala de aula: Perspectivas e Possibilidades. Ijuí: Ed. Unijuí, 2015, 360p

FLÔR, C. C. Na busca de ler para ser nas aulas de Química. Ijuí: Ed Unijuí, 2015, 208 p.

SOLÉ, I., Estratégias de leitura. 6 ed. Porto Alegre: Penso, 1998. 194 p.

WENZEL, J. S.; MARTINS, J. L. de C.; COLPO, C. C.; RIBEIRO, T. A. A prática da leitura no ensino de química: modos e finalidades de seu uso em sala de aula. ACTIO, Curitiba, v. 3, n. 2, p. 98-115, mai./ago. 2018.

WEnZEL, J. S.; MARTINS, J. L. de C.; COLPO, C. C.; A leitura de Textos de Divulgação Científica e a elaboração de perguntas como um caminho para a formação do leitor. Revista de Educação, Ciências e Matemática, v.8, n.2, mai/ago,2018.

WENZEL, J. S.; COLPO, C. C. A leitura de textos de divulgação científica como modo de qualificar o uso da linguagem química no ensino médio. Experiências em Ensino de Ciências, v. 13, n.4, p. 134-143, 2018.

WENZEL, J. S., COLPO, C. C. A prática de leitura interativa na formação inicial de professores de Química. Revista Areté: Revista Amazônica de Ensino de Ciências. v.12, n.25, p. 1- 15, 2019. 